\title{
Determining soil indicators for soil sustainability assessment using principal component analysis of Astan Quds- east of Mashhad- Iran
}

\author{
M. Ghaemi ${ }^{1 *}$, A.R. Astaraei ${ }^{1}$, H. Emami ${ }^{1}$, M. Nassiri Mahalati ${ }^{2}$, S.H. Sanaeinejad ${ }^{3}$ \\ Department of Soil Sciences, Faculty of Agriculture, Ferdowsi University, Mashhad, Iran. *Corresponding \\ author; e-mail: ghaemi27@gmail.com \\ ${ }^{2}$ Department of Agronomy, Faculty of Agriculture, Ferdowsi University, Mashhad, Iran. \\ ${ }^{3}$ Department of Water-Engineering, Faculty of Agriculture, Ferdowsi University, Mashhad, Iran.
}

\begin{abstract}
Soil quality indicators are measurable soil attributes that reveal the soil productivity response or soil-environment functionality that are used to know whether soil quality is improving, remain constant, or declining. These characteristics could be assessed by different indices such as sustainability index approach (SI) based on the threshold levels of soil indicators and cumulative rating approach (CR) based on crop production limitations, which show the sustainability of soil ecosystem in terms of soil degradation. Since Iran is situated in arid and semi-arid climatic conditions, this research was conducted in agriculture fields of southeast of Mashhad, Iran for comparing these two approaches. Sixty three soil samples $(0-30 \mathrm{~cm})$ were collected and nine soil properties such as $\mathrm{pH}$, electrical conductivity (EC), soil organic carbon (SOC), soil particle-size distribution, available water holding capacity (AWHC), bulk density (BD), air capacity (AC), relative field capacity (RFC) and sodium adsorption ratio (SAR) were measured. All these measurements were considered as total data set (TDS). Principal component analysis (PCA) was used to select more effective indicators to conform the minimum data set (MDS). There was a strong correlation between SI and $\mathrm{CR}\left(\mathrm{R}^{2}=0.69, p<0.05\right)$. Only six soil indicators selected as MDS $(\mathrm{pH}, \mathrm{SOC}, \mathrm{AWC}, \mathrm{BD}$ and SAR) were correlated $(p<0.01)$ significantly with SI and CR. These SI and CR results showed more promising effects on soil sustainability. PCA was found a suitable method for selecting the more effective indicators having $\mathrm{R}^{2}=0.77(p<0.05)$ (CR-MDS versus CR-TDS) comparable with $\mathrm{R}^{2}=0.80(p<0.05)$ (CR-MDS versus SI) to use less soil data input in assessing soil quality in arid zone.
\end{abstract}

Keywords: Cumulative rating, minimum data set, soil quality, sustainability index. 


\section{Abbreviations}

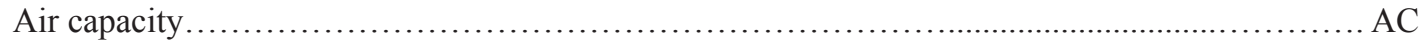

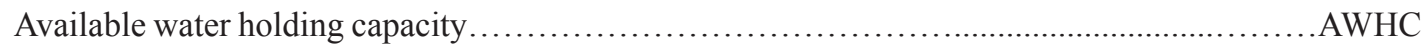

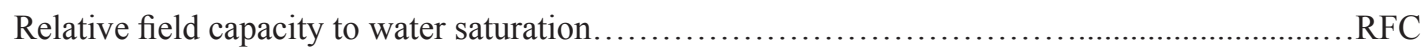

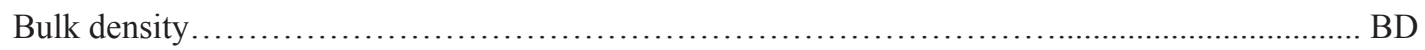

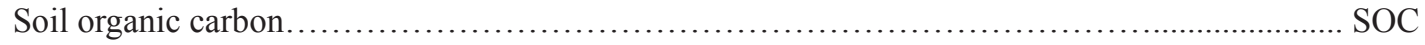

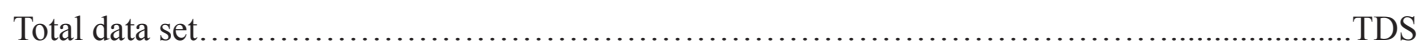

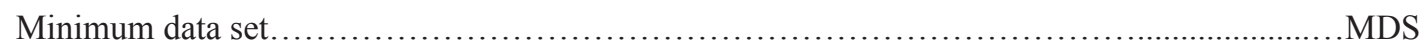

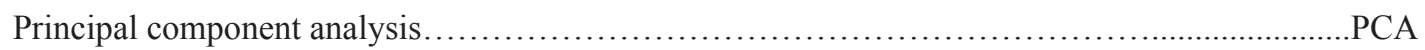

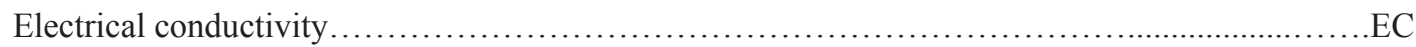

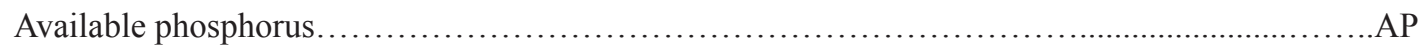

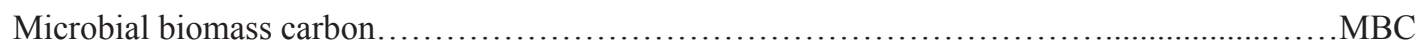

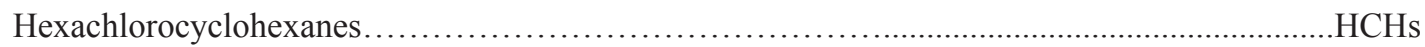

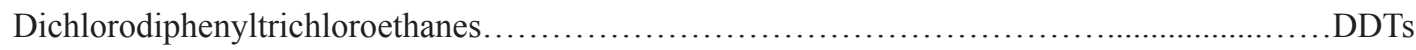

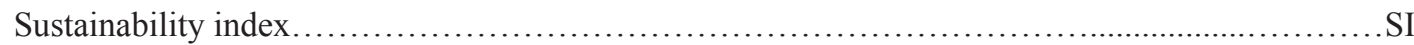

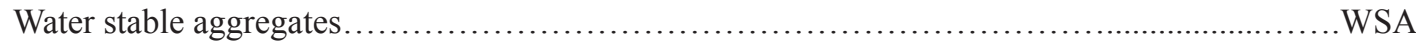

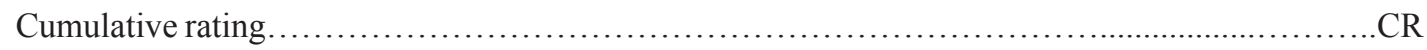

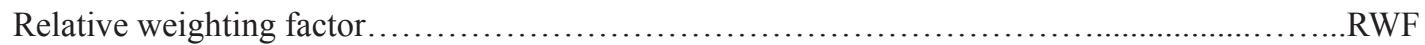

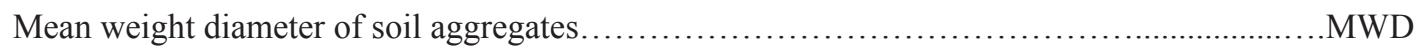

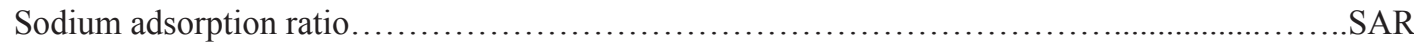

\section{Introduction}

In recent decades, public awareness for understanding and evaluation of environmental changes has been growing rapidly (Scull and Okin, 2007). Soil is one of the most important environmental factors and is considered as the main source in providing essential plant nutrients, water reserves and a medium for plant growth. Soil quality is defined as the capacity of a soil to function within an ecosystem and land-use boundaries, to sustain biological activity, maintain environmental quality, and promote plant, animal, and human health (Doran and Parkin, 1994). Soil quality indices are considered the most common methods for soil quality evaluation due to ease of use, flexibility and quantification. These indices represent the cumulative effects of different soil properties (physical, chemical and ecological) as an index from the role of each indicator in soil quality (Drury et al., 2003; Singh and Khera, 2009).

Agricultural soils with a good physical quality have a stable structure and appropriate 
resistance to the erosion and compaction. They provide a favorable condition for plant growth and development and proliferation of roots and micro-organisms (Reynolds et al., 2002). Soil physical quality is measured by soil indicators such as air capacity (AC), available water holding capacity (AWHC), relative field capacity to water saturation (RFC), macroporosity, bulk density (BD), soil organic carbon (SOC), structural stability index and many others (Reynolds et al., 2009). When soil quality indicators are in the optimum range, crop yield response would be optimal (maximum obtainable yield) with reduced soil degradation (Reynolds et al., 2009). Several authors have proposed various soil quality indicators (Larson and Pierce, 1994; Doran and Parkin, 1994; Karlen et al., 1998) that can be easily measured and they are sensitive to change of soil condition and therefore, they must be able to identify appropriated sustainable soil conditions (Gomez et al., 1996; Aparicio and Costa, 2007). Some researchers have evaluated soil quality based on available soil properties to conform the total data set (TDS) indicator method (Doran and Parkin, 1994; Karlen et al., 1998). Others researchers believed that few representative indicators, called minimum data set (MDS) should be used (Andrews, et al., 2004; Govaerts et al, 2006). Using MDS method in order to select the parameters which better represent the TDS, can save time and money (Govaerts et al, 2006) (Qi et al., 2009). Qi et al. (2009) suggested soil quality indices to evaluate agricultural soil quality in Zhangjiagang as an important County of China. They used the principal component analysis (PCA) for selecting MDS from a total of twenty-two soil properties. Bi et al. (2013) selected a MDS from nineteen physical, chemical and biological soil properties as the TDS ( $\mathrm{pH}$, redox, clay content, ), electrical conductivity (EC), available phosphorus (AP), $\mathrm{NO}_{3}-\mathrm{N}$, SOC, microbial biomass carbon (MBC), $\mathrm{Cd}, \mathrm{Cr}, \mathrm{As}, \mathrm{Pb}, \mathrm{Hg}$, hexachlorocyclohexanes (HCHs), dichlorodiphenyltrichloroethanes (DDTs) and many others) under different planting patterns and soil types. They showed that ten soil properties as $\mathrm{MDS}\left(\mathrm{pH}, \mathrm{EC}, \mathrm{NO}_{3}-\mathrm{N}\right.$, AP, SOC, MBC, Cd, Hg, HCHs and DDTs were highly correlated with TDS and they concluded that the selected MDS had a good efficiency in representing TDS.

Liu et al. (2013) established a soil quality index based on twenty-six soil physical, chemical and microbiological properties in a paddy soil of china by using both TDS and MDS methods. They selected five variables as MDS including arbuscular mycorrhizal fungi, microbial biomass carbon, available silicon, available potassium and total nitrogen and they were significantly correlated with rice yield.

Gomez et al. (1996) proposed the sustainability index (SI) approach to assess soil sustainability in different agricultural management systems. Five soil properties related to soil physical quality were selected including soil depth, AWHC, BD, water stable aggregates (WSA) and SOC. In another approach, Shukla et al. (2004) presented the cumulative rating approach (CR), defined as critical limits of soil physical properties that would be useful to assess the sustainability of agricultural systems at farm scale. These critical levels were categorized from no limitation to extreme limitation in a scale of 1 to 5 , respectively using a relative weighting factor (RWF) based on soil physical quality limitations for the crop production These indicators were AWHC, $\mathrm{BD}$, WSA, AC, infiltration rate, mean weight diameter of soil aggregates (MWD), EC and 
SOC. Singh and Khera (2009) used SI and CR approaches with the same parameters selected by Shukla et al. (2004). The results showed that SI was more suitable than CR for assessing the sustainability in terms of soil erodibility. Emami et al. (2009) and Emami (2012) applied both, SI and CR for soil sustainability assessment in agricultural land of Karaj and Varamin plains in Iran. They used various soil properties (e.g. SOC, MWD, S-value referred to the slope and soil water desorption curve) and many others including the soil texture and sodium adsorption ratio (SAR), $\mathrm{AWHC}, \mathrm{AC}, \mathrm{BD}, \mathrm{pH}, \mathrm{EC}$ and RFC. However, they did not consider a regional suitable indicator method like TDS and MDS. In general, most researchers used a set of predefined soil indicators suggested by Gomez et al. (1996) and Shukla et al. (2004) to assess soil quality and sustainability of agricultural land.

The process of degradation in arid and semiarid regions such as Iran has intensified due to lack of farmers' knowledge of agricultural soil conditions, and lack of proper equipments. Under these conditions, the soil quality is often influenced by limiting factors such as high temperature, poor soil fertility, low AWHC, SOC and high concentrations of salt and pH. As Singh and Khera (2009) pointed out, studying land degradation through the soil quality assessment, that reflects soil functioning within the ecosystems, is crucial for sustainable management of land resources.

The objectives of this study are to: 1) compare SI and CR approaches in evaluating the soil physical quality in terms of soil sustainability in Astan Quds experimental station. The first approach is based on method developed by Gomez et al. (1996) for measuring the sustainability of agricultural systems at farm scale. The second approach is by Shukla et al. (2004) based on the identification of the critical levels of soil indicators by assigning the RWF to assess the sustainability of land use, 2) chose representative regional soil indicators by PCA instead of using a set of pre-defined soil indicators, 3) determine the MDS efficiency as representative of TDS and increase CR approach efficiency through soil data number reduction in calculating CR.

\section{Materials and Methods}

\subsection{Field experiment, data collection and analysis}

Field experiment was carried out on Astan Quds experimental farm which is a unique and known experimental farm situated in east of Mashhad (North East of Iran), geographically located between 36ㅇ $16^{\prime}$ to $36025^{\prime}$ latitude E and 59o 67' to 59o 77' longitude N (Figure 1). According to the climatic classification of Emberger, the farm is located in an arid and semi-arid climate with a mean annual temperature of approximately $14^{\circ} \mathrm{C}$ and mean annual precipitation of about $250 \mathrm{~mm}$. Soils in this area are Aridisols and Entisols, based on soil taxonomy of USDA system (USDA, 1998). The farm lands are irrigated for crops such as alfalfa (Medicago falcata), wheat (Triticum aestivum), barley (Hordecum vulgare), maize (Zea mays) and peas (Cicer arietinum). 


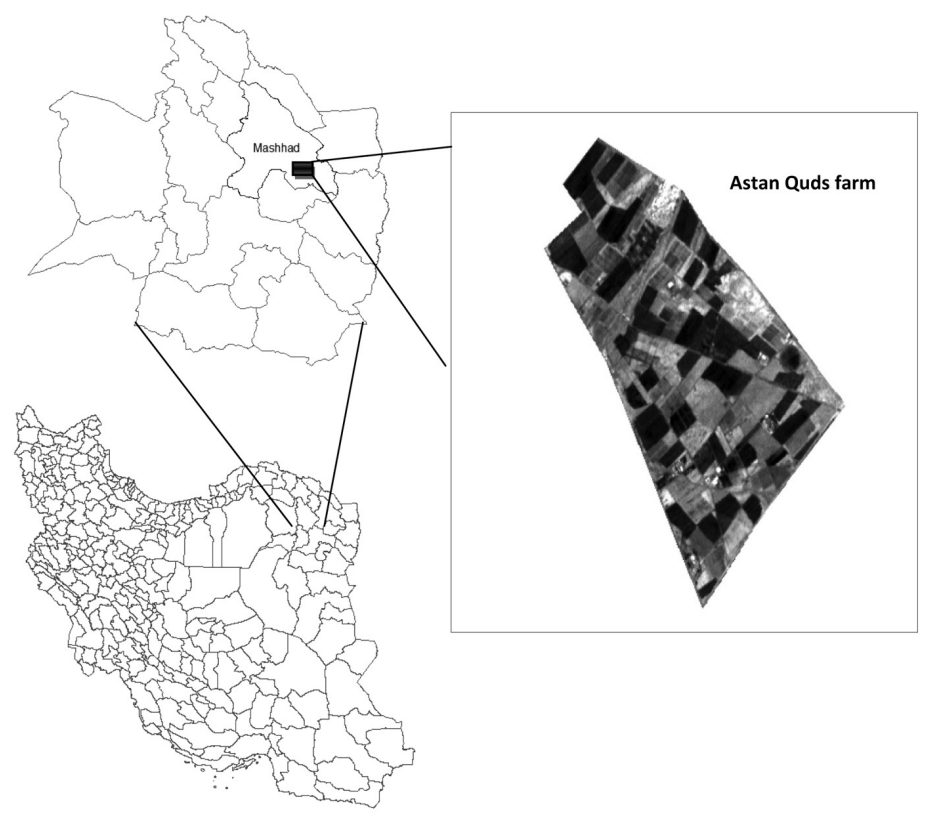

Figure 1. Geographical location of the study area (Latitude $36^{\circ} 16^{\prime}$ to $36^{\circ} 25^{\prime}$ E and longitude $59^{\circ} 67^{\prime}$ to $\left.59^{\circ} 77^{\prime} \mathrm{N}\right)$.

This experiment was conducted in about 5.7 ha field with an irrigated crop rotation of wheat-maize-fallow. Sixty three composited soil samples were collected by systematic soil sampling grid design at $30 \mathrm{~m}$ spacing apart. At each sampling grid cell, five subsamples $(0-30 \mathrm{~cm})$ were taken and mixed to make just one composited sample for further analysis. Undisturbed soil samples were collected by cylinder ( $5 \mathrm{~cm}$ height and $5 \mathrm{~cm}$ diameter) after removing gravels from soil surface. Disturbed samples were transported to the laboratory, air-dried and passed through $2 \mathrm{~mm}$ sieve. Nine soil indicators were considered as TDS for assessing soil quality and sustainability. A total of 63 soil samples were determined using standard laboratory procedures as follow: $\mathrm{pH}$ (METROHM, model 632) and $\mathrm{EC}_{\mathrm{e}}$ (JENWAY,
Model 4310) in saturation extract (Richards, 1954). SOC was determined by Walkely and Black (1934). Soil particle size distribution by Bouyoucos hydrometer method (Gee and Bauder, 1986), AWHC was determined from undisturbed soil core samples by the soil moisture content at $33 \mathrm{kPa}$ and $1500 \mathrm{kPa}$ (Klute and Dirkson, 1986). BD was determined by the core cylinders sampling (Blake and Hartge, 1986) and AC, by the difference between soil water content at saturation $(0 \mathrm{kPa})$ and $10 \mathrm{kPa}$. RFC was determined by dividing the gravimetric water content at field capacity by the saturation water content at saturation (Reynolds, 2009). Finally SAR was calculated as (Richards, 1954):

$S A R=\frac{N a}{\sqrt{\frac{C a+M g}{2}}}$ 
where the soil cations sodium $(\mathrm{Na})$, calcium (Ca) and magnesium $(\mathrm{Mg})$ are expressed in meq $\mathrm{L}^{-1}$. SAR represented the soil sodicity. $\mathrm{SAR}<13$ indicated non sodicity and a values $>13$ indicates sodic soils (Richards, 1954).

\subsection{Soil quality evaluation method}

PCA was used to select the representative soil quality indicators as MDS from the nine indicators as TDS (Doran and Parkin, 1994). Standardized PCA was performed on the correlation matrix as proposed by Andrews et al. (2002) and Govaerts et al. (2006). Principal components (PCs) with eigenvalues $\geq 1$ were considered to contribute to explain greatly the total variability. In each PC, soil indicators with a loading within $10 \%$ of the highest factor loading were chosen as the most appropriate indicators for the MDS (Andrews et al., 2002).

Sustainability index approach was calculated as proposed by Gomez et al. (1996). In this research, soil indicators as MDS was used to calculate SI instead of using a set of pre-defined soil indicators by Gomez et al. (1996). Threshold levels of these soil indicators selected as MDS were calculated based on their mean value of land use at the site. Sustainability indices for these soil indicators, having a positive role in soil sustainability were calculated by dividing the actual soil indicator value by its corresponding threshold value. For soil indicators with a negative role in soil sustainability, the threshold level of each soil indicator was divided by the actual soil indicator values (Singh and Khera,
2009). In this approach, either the positive (e.g. SOC) or negative (e.g. BD) role to sustainability, a higher magnitude of soil indicator shows an improvement in the role soil sustainability. Therefore, values $>1$ shows the positive contribution of the soil indicators in increasing the soil sustainability, while values $<1$ shows a role in reducing the soil sustainability. The SI was calculated as the arithmetic mean values of sustainability indices and the soil samples having SI $>1$ and SI $<1$ were regarded as sustainable and non-sustainable, respectively as proposed by Singh and Khera (2009).

SI is more suggested to CR because it considers less soil indicators; therefore, $\mathrm{CR}$ was calculated based on TDS (CR-TDS= with 9 soil indicators) and MDS (CR-MDS) to test its efficiency. Soil sustainability by using CR approach was calculated by assigning a RWF to each soil indicator values and CR was obtained by summing the RWFs determined on the basis of critical levels ranging from 1 to 5 showing no limitation to extreme limitation classes (Lal, 1994) (Table 1). Then CR was categorized into five classes and each class was assigned to a soil sustainability status (from highly sustainable to unsustainable) (Shukla et al., 2004). Since CR was calculated based on both, MDS (CR-MDS) and TDS (CR-TDS) methods its classification was separately calculated (Table 2). In this study, SAR and RFC were used instead of $\mathrm{K}_{\mathrm{s}}$ and WSA. The relative weighting factor for RFC was carried out as proposed by Reynolds et al. (2009) and SAR was performed as proposed by Alizadeh (2002). 
Table 1. Relative weighting factors (RWF) according to the threshold values of soil quality indicators using the cumulative rating (CR) approach (Lal, 1994)

\begin{tabular}{|c|c|c|c|c|c|c|c|c|c|c|}
\hline Limitation & RWF & $\begin{array}{c}\mathrm{AC}^{1} \\
\left(\mathrm{~cm}^{3} \mathrm{~cm}^{-3}\right)\end{array}$ & $\begin{array}{l}\mathrm{AWHC}{ }^{1} \\
\left(\mathrm{~cm}^{3} \mathrm{~cm}^{-3}\right)\end{array}$ & $\begin{array}{c}\mathbf{B D}^{1} \\
\left(\mathrm{Mg} \mathrm{m}^{-3}\right)\end{array}$ & Texture & $\mathbf{R F C}^{1}$ & $\mathbf{S A R}^{1}$ & $\begin{array}{c}\operatorname{SOC}^{1} \\
\left(\mathrm{Mg} \mathrm{ha}^{-1}\right)\end{array}$ & $\begin{array}{c}\mathbf{E C}^{1} \\
\left(\mathrm{dS} \mathrm{m}^{-1}\right)\end{array}$ & pH \\
\hline None & 1 & $>0.20$ & $>0.30$ & $<1.3$ & Loam & $0.6-0.7$ & $<3$ & $70-130$ & $<3$ & $6-7$ \\
\hline Slight & 2 & $0.18-0.20$ & $0.20-0.30$ & $1.3-1.4$ & $\mathrm{SiL}, \mathrm{Si}, \mathrm{SiCL}$ & $\begin{array}{r}0.5-0.6, \\
0.7-0.75\end{array}$ & $3-6$ & $45-70$ & 3-5 & $\begin{array}{l}5.8-6 \\
7-7.4\end{array}$ \\
\hline Moderate & 3 & $0.15-0.18$ & $0.08-0.20$ & $1.4-1.5$ & $\mathrm{CL}, \mathrm{SL}$ & $\begin{array}{l}0.4-0.5, \\
0.75-0.8\end{array}$ & 6-12 & $14-45$ & $5-7$ & $\begin{array}{l}5.4-5.8, \\
7.4-7.8\end{array}$ \\
\hline Severe & 4 & $0.10-0.15$ & $0.02-0.08$ & $1.5-1.6$ & $\mathrm{SiC}, \mathrm{LS}$ & $\begin{array}{c}0.35-0.4 \\
0.8-0.9\end{array}$ & $12-20$ & $7.5-14$ & $7-10$ & $\begin{array}{l}5.0-5.4, \\
7.8-8.2\end{array}$ \\
\hline Extreme & 5 & $<0.10$ & $<0.02$ & $>1.6$ & $\mathrm{C}, \mathrm{S}$ & $\begin{array}{c}<0.35, \\
>0.9\end{array}$ & $>20$ & $<7.5$ & $>10$ & $\begin{array}{l}<5.0 \\
>8.2\end{array}$ \\
\hline
\end{tabular}

${ }^{1} \mathrm{AC}$ : air capacity; AWHC: available water holding capacity; BD: bulk density; SAR: sodium adsorption ratio; SOC: soil organic carbon; EC: electrical conductivity; RFC: relative field capacity (see definition in the text).

Table 2. Soil sustainability classification based on cumulative rating (CR) approach according to nine soil indicators (TDS) and five soil indicators (MDS).

\begin{tabular}{lccc}
\hline Sustainability & RWF $^{1}$ & CR-TDS $^{2}$ & CR-MDS $^{2}$ \\
\hline Highly sustainable & 1 & $<16$ & $<9$ \\
Sustainable & 2 & $16-21$ & $9-14$ \\
Sustainable with high input & 3 & $21-26$ & $14-19$ \\
Sustainable with another land use & 4 & $26-31$ & $19-24$ \\
Unsustainable & 5 & $>31$ & $>24$ \\
\hline
\end{tabular}

${ }^{1}$ RWF: relative weighting factors.

${ }^{2} \mathrm{CR}$-TDS: cumulative rating calculated based on nine soil indicators as TDS; CR-MDS: cumulative rating calculated based on five soil indicators as MDS.

Correlation coefficients and regression analyses at significant levels $<0.05$ and $<0.01$ were conducted amongst SI, CR and soil quality indicators to see the positive or negative significant relationships between each studied soil indicator with CR and SI and correlation coefficients (r) obtained indicating its good or poor relations. The regression analyses was performed between SI and CR-TDS to obtain their closeness for evaluating soil sustainability and thereafter, regression equations were developed with respect to highly significant $\mathrm{R}^{2}$ values. We also determined the efficiency of selected indicators constituting the MDS (CRMDS) over the TDS (CR-TDS) based on highly significant $\mathrm{R}^{2}$ value.

\section{Results}

Descriptive statistics of soil properties (Table 3) indicated that SOC, EC, SAR and clay content had the highest variability at 
field scale. In order to calculate the SI, soil effective indicators were selected by PCA to obtain MDS (Table 4). The results showed that the first four PCs with eigenvalue $\geq 1$ accounted for $75 \%$ of the total variance (Table 4). Within each PC, the variable with the highest factor loading was selected as the most important contributor to the $\mathrm{PC}$ for MDS. In $\mathrm{PC}_{1}, \mathrm{PC}_{2}$ and $\mathrm{PC}_{3}, \mathrm{SAR}, \mathrm{BD}$ and $\mathrm{pH}$ had the highest factor loadings, respectively. $\mathrm{PC}_{4}$ presented two high weighted indicators, AWHC and SOC, which in turn were highly correlated $(\mathrm{r}=0.813, \mathrm{P}<0.01$, see Table 5) and these indicators were also selected for MDS.

Table 3. Soil properties of studied soil samples $(n=63)$

\begin{tabular}{lcccc}
\hline Variables $^{1}$ & Min $^{2}$ & Max $^{2}$ & Mean & $\mathbf{C V}^{2}$ \\
\hline EC $\left(\mathbf{d S ~ m}^{-1}\right)$ & 1.2 & 3.82 & 2.69 & 39.43 \\
pH & 7.2 & 7.93 & 7.54 & 3.02 \\
SOC (\%) & 0.31 & 1.52 & 0.88 & 28.53 \\
SAR & 2.49 & 8.06 & 4.92 & 37.91 \\
Clay (\%) & 4.42 & 24.72 & 15.32 & 34.66 \\
Silt (\%) & 40 & 56 & 48.47 & 8.03 \\
Sand $(\%)$ & 29.28 & 43.18 & 36.20 & 9.14 \\
AWHC $\left(\mathbf{c m}^{3}\right.$ & 0.13 & 0.21 & 0.16 & 12.87 \\
BD $\left(\mathbf{M g ~ m}^{-3}\right)$ & 1.32 & 1.55 & 1.43 & 4.61 \\
AC $\left(\mathbf{c m}^{3} \mathbf{c m}^{-3}\right)$ & 0.15 & 0.27 & 0.21 & 12.22 \\
RFC & 0.45 & 0.63 & 0.55 & 7.90 \\
\hline
\end{tabular}

${ }^{1}$ EC: electrical conductivity; SOC: soil organic carbon; SAR: sodium adsorption ratio; AWHC: available water holding capacity; BD: bulk density; AC: air capacity; RFC: relative field capacity (see definition in the text).

2Min: minimum value; Max: maximum value; $\mathrm{CV}$ : coefficient of variation;

Table 4. Principal component analysis to select the soil indicators as the minimum data set (MDS) (underlined value) from studied soil samples $(n=63)$.

\begin{tabular}{|c|c|c|c|c|}
\hline Component & $\mathrm{PC}_{1}{ }^{2}$ & $\mathrm{PC}_{2}$ & $\mathrm{PC}_{3}$ & $\mathrm{PC}_{4}$ \\
\hline Eigenvalue & 3.03 & 2.34 & 1.71 & 1.18 \\
\hline Percent & 27.55 & 21.29 & 15.60 & 10.72 \\
\hline Cumulative percent & 27.55 & 48.83 & 64.46 & 75.17 \\
\hline Variables $^{1}$ & \multicolumn{3}{|c|}{ Eigenvectors } & \\
\hline Sand (\%) & -0.191 & 0.399 & 0.288 & 0.111 \\
\hline Clay (\%) & 0.155 & 0.379 & 0.484 & -0.072 \\
\hline Silt (\%) & 0.286 & 0.223 & 0.271 & -0.212 \\
\hline AWHC $\left(\mathrm{cm}^{3} \mathrm{~cm}^{-3}\right)$ & 0.347 & 0.172 & -0.196 & $\underline{0.431}$ \\
\hline pH & 0.339 & -0.177 & $\underline{-0.516}$ & 0.302 \\
\hline $\mathrm{EC}\left(\mathrm{dS} \mathrm{m}^{-1}\right)$ & 0.503 & -0.115 & 0.116 & -0.288 \\
\hline SAR & $\underline{0.518}$ & -0.129 & 0.174 & -0.293 \\
\hline BD $\left(\mathbf{M g ~ m}^{-3}\right)$ & 0.022 & $\underline{0.475}$ & 0.262 & 0.377 \\
\hline$A C\left(\mathrm{~cm}^{3} \mathrm{~cm}^{-3}\right)$ & -0.051 & 0.382 & -0.359 & -0.315 \\
\hline RFC & 0.094 & 0.401 & -0.126 & -0.276 \\
\hline $\operatorname{SOC}(\%)$ & 0.319 & 0.154 & -0.250 & $\underline{0.437}$ \\
\hline
\end{tabular}

${ }^{1}$ EC: electrical conductivity; SOC: soil organic carbon; SAR: sodium adsorption ratio; AWHC: available water holding capacity; BD: bulk density; AC: air capacity; RFC: relative field capacity (see definition in the text). 
Our results indicated that $40 \%$ of soil samples had SI $<1$, therefore an unsustainable status in this management system (Figure 2) and 38 soil samples $(60 \%)$ were grouped as sustainable. Correlation between SI and soil indicators as MDS (Table 5) indicated that AWHC $(\mathrm{r}=0.835, P<0.01)$ and SOC $(\mathrm{r}=0.806$,
$P<0.01$ ) had the highest correlation with SI. The distribution of sustainability indices in the studied soil samples varied between $32 \%$ and $60 \%$ representing unsustainable status, being AWHC the most important one compared with $\mathrm{pH}$ that presented $32 \%$ only (Figure 2).

Table 5. Pearson's correlation coefficients between cumulative rating (CR) and soil indicators (TDS and MDS) and the correlation coefficients between sustainability Index (SI) and soil indicators (MDS)

\begin{tabular}{|c|c|c|c|c|c|c|c|c|c|c|c|c|c|}
\hline Variables $^{1}$ & AWHC & BD & AC & SOC & Sand & Clay & Silt & pH & EC & SAR & RFC & CR & $\mathrm{SI}^{2}$ \\
\hline AWHC $^{4}$ & & $-0.422^{* *}$ & $0.386^{* *}$ & $0.813^{* *}$ & $-0.163^{\circ}$ & $0.441^{*}$ & $-0.462^{* *}$ & $-0.803^{* *}$ & $-0.713^{* *}$ & $-0.788^{* *}$ & $0.700^{* *}$ & $-0.806^{* *}$ & $0.835^{* *}$ \\
\hline $\mathbf{B D}^{4}$ & & & $-0.607^{* *}$ & $-0.281^{* *}$ & $0.625^{* *}$ & $-0.737^{* *}$ & $0.474^{* *}$ & $0.399^{* *}$ & $0.471^{* *}$ & $0.517^{* *}$ & $0.211^{\circ}$ & $0.608^{* *}$ & $-0.497^{*+}$ \\
\hline AC & & & & $0.438^{* *}$ & $0.473^{* *}$ & $0.334^{* *}$ & $-0.053^{\text {ns }}$ & $0.271^{* *}$ & $-0.081^{\text {ns }}$ & $-0.172^{*}$ & $-0.903^{* *}$ & $-0.085^{\text {ns }}$ & -3 \\
\hline $\operatorname{soc}^{4}$ & & & & & $-0.061^{\text {ns }}$ & $0.358^{* *}$ & $-0.436^{* *}$ & $-0.729^{* *}$ & $-0.560^{* *}$ & $-0.686^{* *}$ & $0.697^{* *}$ & $-0.711^{* *}$ & $0.806^{* *}$ \\
\hline Sand & & & & & & $-0.682^{* *}$ & $0.080^{\mathrm{ns}}$ & $0.022^{\mathrm{ns}}$ & $0.203^{*}$ & $0.249^{*}$ & $0.250^{\circ}$ & $0.298^{* *}$ & - \\
\hline Clay & & & & & & & $-0.783^{* *}$ & $-0.417^{* *}$ & $-0.478^{* *}$ & $-0.648^{* *}$ & $-0.017^{\text {ns }}$ & $-0.589^{* *}$ & - \\
\hline Silt & & & & & & & & $0.549^{* *}$ & $0.624^{*}$ & $0.672^{* *}$ & $-0.188^{\circ}$ & $0.549^{* *}$ & - \\
\hline $\mathrm{pH}^{4}$ & & & & & & & & & $0.761^{* *}$ & $0.864^{* *}$ & $-0.547^{* *}$ & $0.830^{* *}$ & $-0.766^{* *}$ \\
\hline EC & & & & & & & & & & $0.897^{* *}$ & $-0.429^{* *}$ & $0.811^{* *}$ & - \\
\hline $\mathbf{S A R}^{4}$ & & & & & & & & & & & $-0.486^{\circ "}$ & $0.883^{* *}$ & $-0.785^{* *}$ \\
\hline RFC & & & & & & & & & & & & $-0.423^{* *}$ & - \\
\hline
\end{tabular}

${ }^{1} \mathrm{EC}$ : electrical conductivity; SOC: soil organic carbon; SAR: sodium adsorption ratio; AWHC: available water holding capacity; BD: bulk density; AC: air capacity; RFC: relative field capacity (see definition in the text).

${ }^{2}$ SI: the mean value of land use at the site for each soil indicator of MDS was then considered as the threshold levels. Sustainability indices for these soil indicators were calculated based on these threshold values. SI was determined as arithmetic mean values of the sustainability indices.

${ }^{3}(-)$ : In SI column dash sign (-) representing parameters shown in column 1 were not used in calculating SI.

${ }^{4}$ Soil indicators were selected as MDS from nine soil indicator as TDS

- * and **: significant levels at $p<0.05$ and $p<0.01$

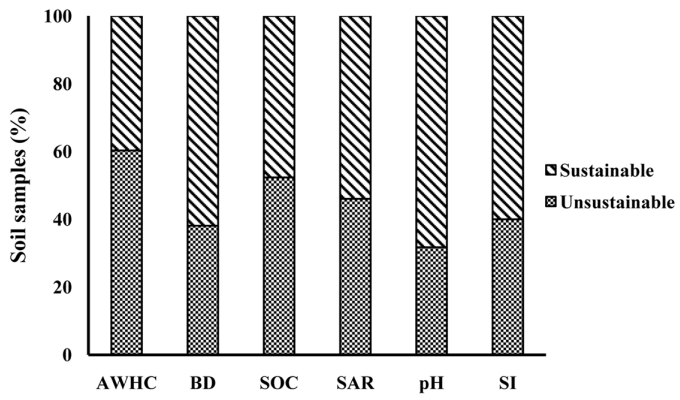

Figure 2. Soil Sustainability Index (SI) approach calculated from the means of soil quality indicators: AWHC: available water holding capacity; BD: bulk density; SOC: soil organic carbon; SAR: sodium adsorption ratio; $\mathrm{pH}$ to form the minimum data set (MDS) selected from studied soil samples $(n=63)$. 
The RWF shows that soil texture classes varied between loam $(66 \%)$ with no limitation considering in class 1 to silt loam (33\%) with slight limitation considering in class 2 (Figure 3). BD of $59 \%$ of soil samples representing moderate and severe limitations. The AC of $43 \%$ of soil samples representing no limitation, $32 \%$ of soil samples had slight limitation and the rest 25\% had moderate limitation (Figure 3 ). The correlation coefficients obtained between $\mathrm{AC}$ and soil particles size (sand $\mathrm{r}=0.47, \mathrm{P}<0.01$ and clay $\mathrm{r}=0.33, \mathrm{P}<0.01)$ and the $\mathrm{BD}(\mathrm{r}=-0.61$, $\mathrm{P}<0.01$ ) representing $\mathrm{AC}$ can be influenced by the soil particle size and the bulk density (Table 5). Total soil samples had moderate limitation in terms of the AWHC. RFC with the slight and moderate limitation classes $(86 \%$ of soil samples) showed similar trend as AWHC.

SOC as one of the most important indicators in soil quality had slight and moderate limitation in $76 \%$ of soil samples. In addition, $50 \%$ of soil samples had slight limitation in terms of EC and SAR of $85 \%$ of soil samples had slight and moderate limitations (Figure 3). About $81 \%$ of soil samples had moderate to severe limitation with respect to $\mathrm{pH}$, due to the calcareous nature of soils (Figure 3). Accordingly, 56\% soil samples were sustainable and highly sustainable in terms of CR-TDS and $44 \%$ of soil samples would be sustainable, if more inputs to the agricultural system were regarded (Figure 4). However, about $65 \%$ soil samples were classified as sustainable and highly sustainable with respect to CR-MDS and $35 \%$ as potentially sustainable with more input (Figure 4). Results of linear regression analysis showed that SI was negatively correlated with CR-TDS $\left(\mathrm{R}^{2}=0.69\right.$, $\mathrm{P}<0.05$ ) (Figure 5). The regression between CR-TDS and CR-MDS $\left(\mathrm{R}^{2}=0.78, P<0.05\right)$ was highly significant $(P<0.05)$ and proved that MDS has a good efficiency in representing TDS (Figure 6a). The linear relationship between SI and CR-MDS was highly significant $(P<0.05)$ either and it indicated (Figure $6 \mathrm{~b}$ ) that SI had higher correlation with CR-MDS $\left(\mathrm{R}^{2}=0.803, P\right.$ $<0.05$ ) than CR-TDS proved that soil indicators selected as MDS had very good efficiency in assessing soil quality compared to TDS.

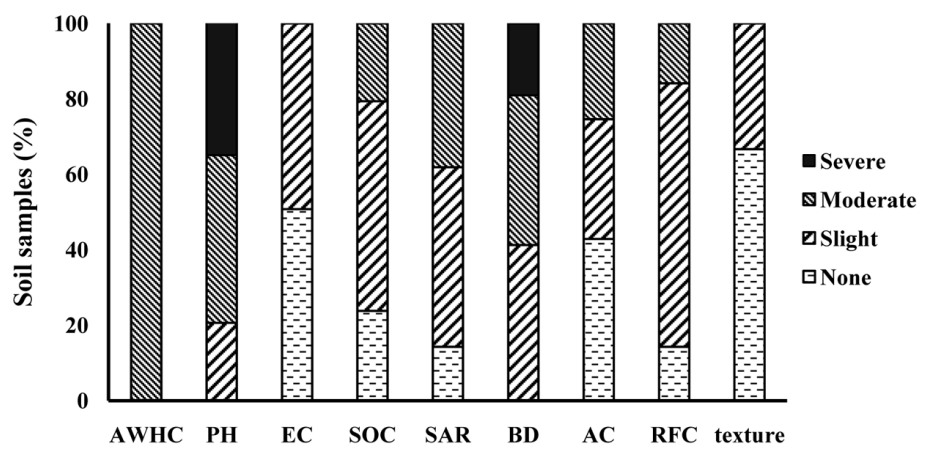

Figure 3. Soil physical quality limitations calculated by relative weighting factors (RWF) in Cumulative rating (CR) approach for nine soil indicators as total data set (TDS) including AWHC: available water holding capacity; $\mathrm{pH}$; EC: electrical conductivity; SOC: soil organic carbon; SAR: sodium adsorption ratio; BD: bulk density; AC: air capacity; RFC: relative field capacity; Texture (sand, silt and clay), selected from studied soil samples $(n=63)$ Discussion. 


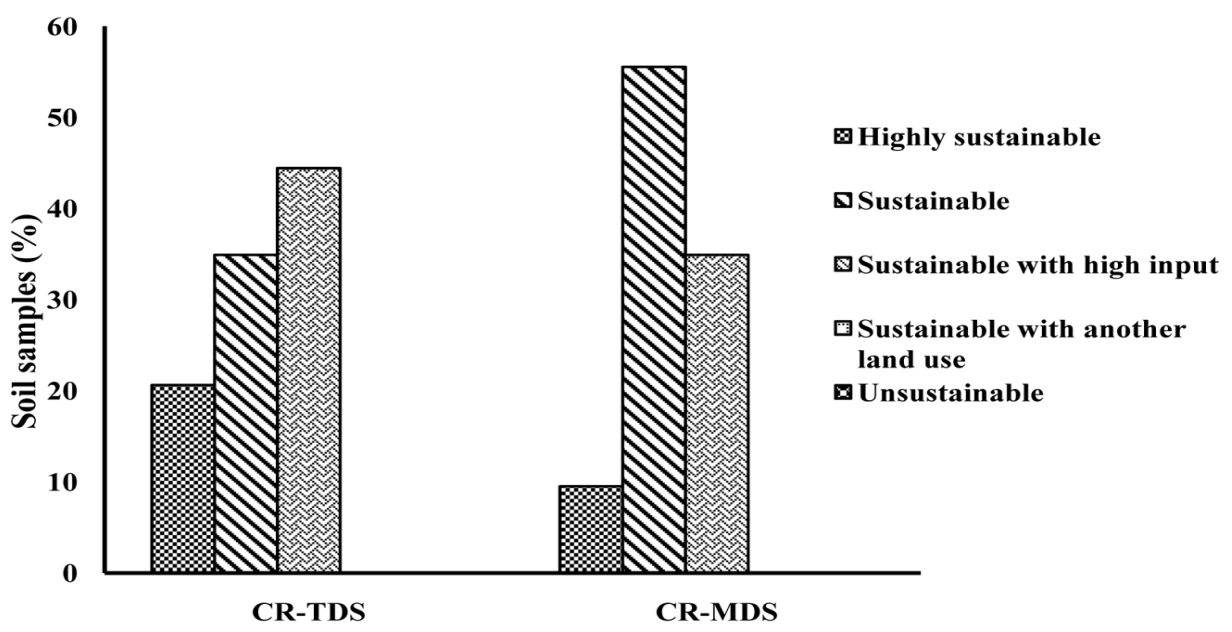

Figure 4. Soil sustainability based on cumulative rating (CR) approach calculated based on Total data set (TDS) (CR-TDS) and Minimum data set (MDS) (CR-MDS) selected from studied soil samples $(n=63)$

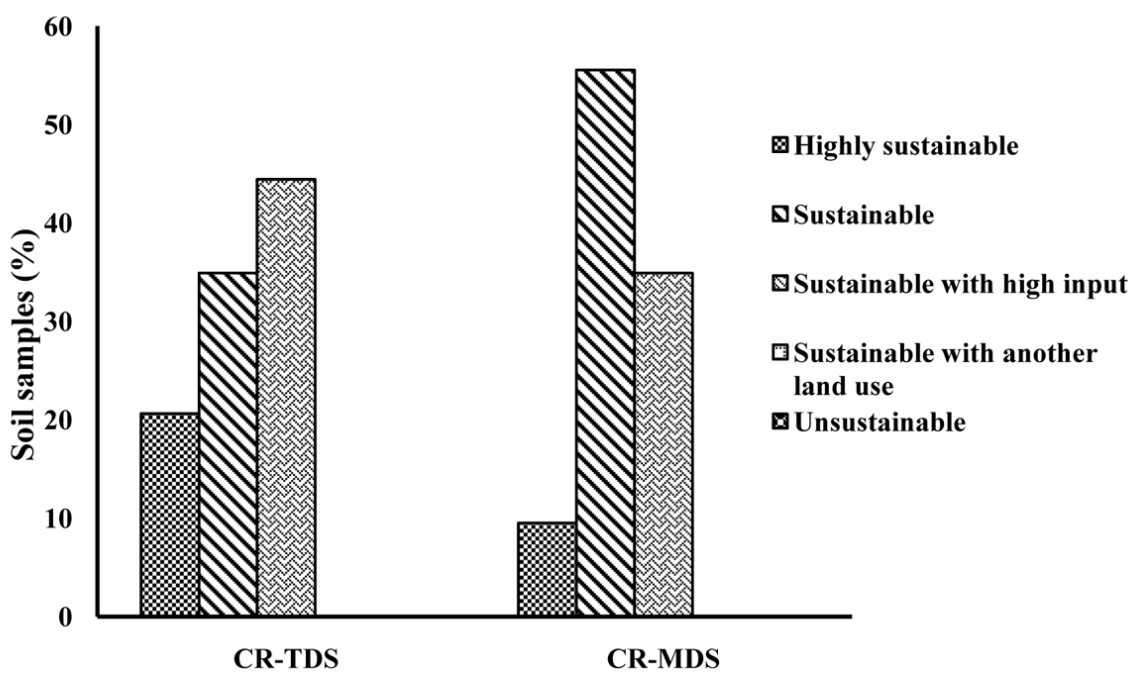

Figure 5. Relationship between Sustainability Index (SI) and Cumulative Rating (CR) based on nine soil indicators as total data set (TDS) (CR-TDS) selected from studied soil samples $(n=63)$. 

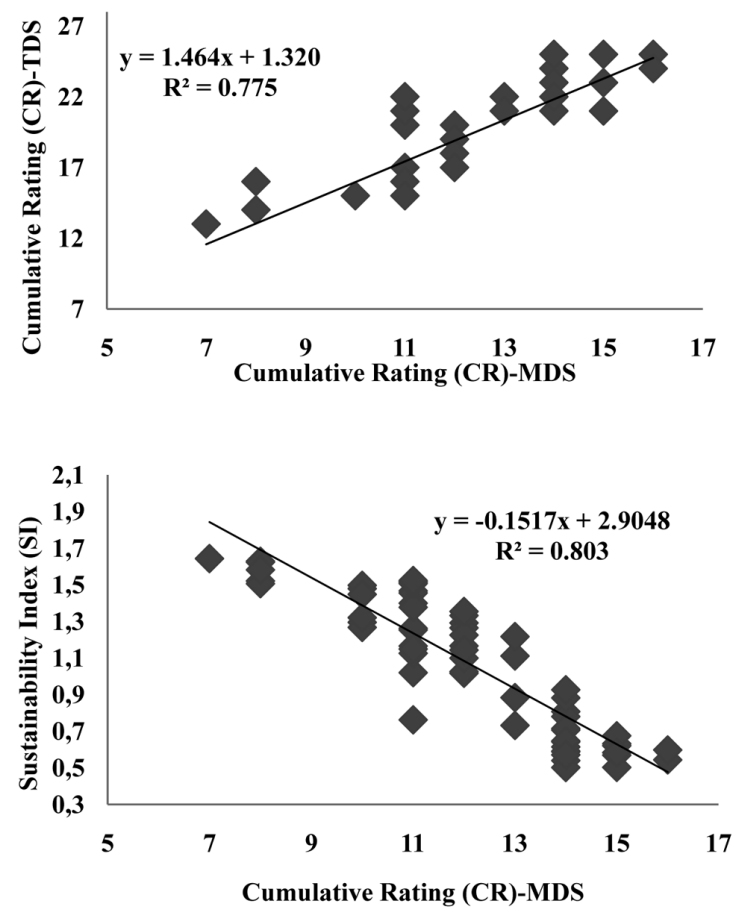

Figure 6. Relationship between Sustainability Index (SI) and Cumulative Rating (CR) calculated based on Total data set (TDS) and Minimum data set (MDS) selected from studied soil samples $(n=$ 63), (a) CR approach using TDS (CR-TDS) and MDS (CR-MDS) and (b) between SI and CR-MDS.

\section{Discussion}

We hypothesize that soil quality indices are considered the most appropriated methods for soil sustainability evaluation due to ease of use, flexibility and quantification (Drury et al., 2003; Singh and Khera, 2009). Selecting MDS soil indictors can perform as well as TDS evaluation saving time and money (Govaerts et al, 2006; Qi et al., 2009; Rahmanipour et al., 2014). In this study, instead of using a set of predefined soil indicators by Gomez et al. (1996) and Singh and Khera (2009), a site-specific selection of soil properties as MDS was used. However, several MDS have been proposed (Shukla et al., 2006; Yang et al., 2010). Suitable methods to identify appropriate soil quality indicators seem to be important due to their significant impact on soil functionalities and productivity (Ditzler and Tugel, 2002). Methods for identification and determination of MDS include linear and multiple regression analysis (Li and Lindstorm, 2001), scoring functions (Yang et al., 2010), principal component (Qi 
et al., 2009) and discriminant analysis (Lima et al., 2008). Among these methods, PCA was employed as a data reduction tool to select the most appropriate indicators (Doran and Parkin, 1994). This technique groups soil indicators into a few factors as PCs accounts for total variance (Johnson and Wichern, 2002). PCs with eigenvalue $\geq 1$ were regarded for selection of MDS and the soil indicators with highest factor loading were selected as the most important contributor to each PC for MDS. However, in this study indicators from expert opinions along PCA were considered for selecting effective soil indicators as MDS. Dalal and Moloney (2000) and Andrews et al. (2002a) reported that choice among well-correlated variables could also be based on the practicability of the variables. Hence, any expert could employ the options to select or eliminate the indicators from the final MDS based on their simplicity of sampling, measurement cost and interpretation of results. Regression coefficients obtained between SOC, AWHC, AC, RFC, pH, EC and SAR (Table 5) showed significant relationships with soil physical and chemical indicators. These variables positively impacted the physical quality of soil by improving soil structural stability and biological properties as reported by many authors (Shukla et al., 2006; Yao et al., 2013; Liu et al., 2013). Because of the importance of SOC for soil quality, it was selected in this study. The highly significant correlation coefficients obtained amongst pH, EC, RFC, SAR, AWHC, $\mathrm{AC}$ and SOC indicates its impact on other soil indicators (Table 5). Thus, it can be concluded that SOC is one of key indicators affecting the soil quality and sustainability in the studied area, which is consistent with the findings of Govaerts et al. (2006), Lal et al. (1999) and Gregorich et al. (1997).

Shukla et al. (2006) selected SOC as the most dominant soil attribute in their study. Lima et al. (2008) used PCA as a multivariate statistical method for selecting effective soil quality indicators. They retained eight soil properties (BD, AWHC, Cu, Zn, Mn, SOC, earthworms and MWD) as the MDS for rice production systems. Govaerts et al. (2006) defined similar dataset including eight physical and chemical indicators (time-to-pond (i.e. Direct surface infiltration), aggregate stability, permanent wilting point, topsoil penetration resistance, SOC, soil N, $\mathrm{K}$ and $\mathrm{Zn}$ concentrations) each for highland soil. Yemefack et al. (2006) selected five soil properties $(\mathrm{pH}$, exchangeable calcium, available phosphorous, $\mathrm{BD}$ and $\mathrm{SOC}$ ) to characterize soil dynamics in shifting cultivation systems. Yao et al. (2013) proposed five soil properties (SOC density, $\mathrm{SOC}, \mathrm{Na}, \mathrm{Cl}$, water table and $\mathrm{EC}$ of groundwater) for soil quality assessment of typical salt-affected farmland. Therefore, all of them used SOC in the MDS, which is in agreement with our results.

Five variables from four PCs with eigenvalue $\geq 1$, including BD, AWHC, SOC, $\mathrm{pH}$, and SAR were selected as the most effective soil indicators (Table 4), which are consistent with some of the parameters described by Gomez et al. (1996). This reveals that selection of the effective indicators soil physical quality for a given study area, provides a comprehensive understanding of soil conditions. Similar selected soil indicators were proposed by Emami et al. (2012) and Singh and Khera (2009). The characterization of soil quality requires a selection of the most sensitive indicators as decision support tools 
to changes soil management practices (Elliott, 1994). Arshad and Coen (1992) suggested that soil depth up to root restricting layer, aggregate stability, AWHC, BD or PR, $\mathrm{K}_{\mathrm{s}}$, SOC, pH, EC and nutrient availability are generally sensitive to management practices, thus they can be used as soil quality indicators. As presented in this study the soil properties such as, AWHC, BD and SOC represent the most important soil quality indicators as described by Topp et al. (1997) and also Reynolds et al. (2009).

Our results indicated that $40 \%$ of soil samples had unsustainable status for sustainable agriculture in this management system with respect to SI. Emami (2012) reported that $47.1 \%$ of soil samples in Karaj plain were not suitable for agricultural land use. The negative correlation between SI and bulk density ( $\mathrm{r}=$ -0.497, $\mathrm{P}<0.01$ ) showed that the increase in bulk density can reduce soil sustainability. In conventional systems before sowing spring and fall crops, tillage and disking are normally conducted with an excessive use of agricultural machineries that increase the soil bulk density. Soil samples (59\%) had moderate and severe limitations with respect to BD reflecting poor soil physical quality, similar findings was reported by Virto et al. (2010). Therefore, in the conventional farming system, the selection of bulk density for determining soil sustainability index seems to be very important and necessary. The results of the sustainability indices of each indicator showed AWC and SOC are the main limiting factors of soil quality in the study area due to their higher correlation coefficients with SI approach (Table 5). Studies in Karaj and Varamin plains have confirmed our finding (Emami et al. 2012).About $81 \%$ of studied soils showed moderate to severe limitations in terms of $\mathrm{pH}$, indicating the presence of calcareous soils (Figure 3). Since soil nutrients uptake by plants decrease dramatically in the presence of high $\mathrm{pH}$ (Salardini, 1995), $\mathrm{pH}$ can be considered as one of the effective soil indicators reducing soil physical quality.

The results of CR-TDS showed that $44 \%$ of soils would be potentially sustainable if more input is included in the agricultural system. Thus, the implementation of appropriate management strategies such as use of organic wastes, reduction of soil tillage, and inclusion of legumes in crop rotations, partly can improve soil sustainability and quality. Niu et al. (2011) showed that spreading out straw on soil surface before tillage and leaving straw at soil surface without tillage, these are two advantageous practices to increase SOC accumulation in the surface layer to improve soil quality.

The relationship between SI and CR-TDS $\left(\mathrm{R}^{2}=0.69, \mathrm{P}<0.05\right)$ proved both indices had good efficiency in determining soil quality (Figure 5). These approaches were negatively correlated with each other as it was expected. As reported by Singh and Khera (2009) higher SI indicated soil quality improvement and higher $\mathrm{CR}$ indicated poor soil quality as obtained in our study. Emami et al. (2012) also reported highly negative correlation between SI and CRTDS. Based on CR-TDS results in this study, soil indicators such as $\mathrm{SOC}, \mathrm{AWC}, \mathrm{BD}, \mathrm{pH}$ and SAR were the most important factors limiting sustainable condition. This was supported by the significant correlations between these soil indicators and CR-TDS.

SI is preferred to CR-TDS because it was established with less soil indicators. The 
results of Singh and Khera (2009) showed that SI and CR were significantly correlated to soil erodibility, but the SI index demonstrated to be better as it require less soil indicators with high soil erodibility correlation. Therefore, multivariate analyses technique of PCA was used in this study to reduce the number of effective soil indicators and to increase efficiency of CR approach for soil sustainability assessment.

The results of CR-MDS were comparatively similar to the CR-TDS, since CR-MDS showed only $10 \%$ difference compared to CR-TDS (Figure 4). The differences between CR-TDS and CR-MDS and the high correlation coefficients between $\mathrm{CR}$ approach and soil indicators considered as MDS (Table 5) demonstrated that five soil indicators $\mathrm{SOC}, \mathrm{AWC}, \mathrm{BD}, \mathrm{pH}$ and SAR are the key parameters for evaluating the soil sustainability.

The relationship between CR-MDS and CRTDS $\left(\mathrm{R}^{2}=0.78, \mathrm{P}<0.05\right)$ indicated that the MDS is a good representative of nine soil indicators (TDS) (Figure 6a). Moreover, using PCA for selecting more effective soil indicators as MDS can increase the efficiency of $\mathrm{CR}$ as it provide using less soil data input in assessing soil quality. Thus, it seems that the selected soil indicators used in calculation SI approach and CR-MDS are the most important indicators affecting soil sustainability in the study area (Figure 6b). Mandal et al. (2008) applied PCA for evaluating impact of irrigation water quality on a calcareous clay soil. Their results showed that PCA as a multivariate statistical method is a suitable tool for selecting effective soil indicators as MDS. Our results showed that using PCA to select the MDS from initial large of TDS is in good agreement with the results of Govaerts et al. (2006) and Shukla et al. (2006). The soil quality indices can be applied to monitor soil sustainability changes instead of using the common definitions of soil quality indicators such as soil physical and chemical properties and their processes (Lee et al., 2006).

\section{Conclusions}

The results of present research showed that agricultural land use and improper management practices have led to degradation of soil quality. Also, both sustainability index and cumulative rating approaches indicated similar results in evaluating soil sustainability. The use of this type of indices can help the policymakers, researchers, and farmers to take decisions on selection of management strategies and to monitor the changes in soil quality. Results demonstrated that the site-specific selection of soil indicators in assessing soil quality and sustainability instead of considering a set of pre-defined soil indicators of soil sustainability can provide a better comprehensive understanding of soil conditions. The results showed that minimum data set method could adequately represent total data set method with respect to saving time and money. Principal component analysis as a multivariate statistical method increased the efficiency of cumulative rating approach as it uses less soil data input to assess soil quality. Principal component analysis was found, therefore to be a suitable method for selecting more effective indicators, which have key roles in soil sustainability. 


\section{References}

Alizadeh, A. 2002. Water, Soil and plant relationship. Astane quds publication, $2^{\text {nd }} \mathrm{Ed}$, $353 \mathrm{p}$.

Andrews, S.S., Karlen, D.L., Mitchell, J.P. 2002. A comparison of soil quality indexing methods for vegetable production systems in northern California. Agr Ecosyst Environ. 90, 25-45.

Andrews, S.S., Mitchell, J.P., Mancinelli, R., Karlen, K.L., Hartz, T.K., Horwath, W.R., Pettygrove, G.S., Scow, K.M., Munk, D.S. 2002. On-farm assessment of soil quality in California's central valley. Agron. J. 94, $12-23$.

Aparicio, V., Costa, J.L., 2007. Soil quality indicators under continuous cropping systems in the Argentinean pampas. Soil Till Res. 96, 155-165.

Arshad, M.A., Coen, G.M. 1992. Characterization of soil quality: Physical and chemical criteria. Am. J. Alternative Agr. 7, 25-31.

Bi, C.J., Chen, Z.L., Wang, J., Zhou, D. 2013. Quantitative assessment of soil health under different planting patterns and soil types. Pedosphere. 23, 194-204.

Cox, M.S., Gerard, P.D., Wardlaw, C., Abshire, M.J. 2003. Variability of selected soil properties and their relationships with soybean yield. Soil Sci Soc Am. J. 67, 12961302.

Dalal, R.C., Moloney, D. 2000.Sustainability indicators of soil health and biodiversity. In: Hale, P., Petrie, A., Moloney, D., Sattler, P. (Eds.), Management for Sustainable Ecosystems, Centre for Conservation
Biology. The University of Queensland, Brisbane, pp: 101-108.

Ditzler, C.A., Tugel, A.J. 2002. Soil quality field tools: Experiences of USDA-NRCS soil quality institute. Agron. J. 94, 33-38.

Doran, J.W., Parkin, B.T. 1994. Defining and assessing soil quality. In: Doran, J.W., Coleman, D.C., Bezdicek, D.F., Stewart, B.A. (Eds.), Defining Soil Quality for a Sustainable Environment. Soil Science Society of America, Inc., Madison, WI, USA, pp: 3-21.

Drury, C.F., Zhang, T.Q., Kay, B.D. 2003. The non-limiting and least limiting water range for soil nitrogen mineralization. Soil Sci Soc Am J. 67, 1388-1404.

Elliott, E.T. 1994. The potential use of soil biotic activity as an indicator of productivity, sustainability and pollution. In: Pankhurst, C.E., Doube, B.M., Gupta, V.V.S.R., Grace, P.R., (Eds.), Soil Biota: Management in Sustainable Farming Systems. CSIRO, Melbourne, pp: 250-256.

Emami, H., Mahdi Shorafa, M., Neyshabouri, M. R., Liaghat, A. L. 2009. Prediction of Soil physical quality index by using of conveniently measurable soil properties in some saline and calcareous soils. Ir. J. Soil Water Res. 39. 39-46.

Emami, H. 2012. Study sustainability situation of Karaj plain soils in agricultural land use. Ir. J. Soil Res. 26, 245-254.

Emami, H., Neyshabouri, M. R., Shorafa, M. 2012. Relationships between some soil quality indicators in different agricultural soils from Varamin, Iran. J. Agr Sci Technology. 14, 951-959. 
Gee, G.W., Bauder, J.W. 1986. Particle size analysis. In: Klute, A. (Ed.), Methods of Soil Analysis. Part 1, 2nd ed., Agron. Mono-graph No. 9. ASA, Madison WI, pp: 337-382.

Gomez A.A., Kelly, D.E.S., Syers, J.K., Coughlan, K.J. 1996. Measuring sustainability of agricultural systems at farm level. In: Doran J.W. and Jones A.J., Eds. Methods for assessing soil quality. SSSA Special Publication Number 49, Soil Science Society of America, INC., Madison, WI, pp: 401-410

Govaerts, B., Sayre, K.D., Deckers, J. 2006. A minimum data set for soil quality assessment of wheat and maize cropping in the highlands of Mexico. Soil Till Res. 87, 163-174.

Gregorich, E.G., Carter, M.R., Doran, J.W., Pankhurst, C.E., Dwyer, L.M. 1997. Biological attributes of soil quality. In: Gregorich, E.G., Carter, M.R. (Eds.), Soil Quality for Crop Production and Ecosystem Health. New York, NY, pp. $81-114$.

Johnson, R.A., Wichern, D.W. 1992. Applied multivariate statistical analysis. PrenticeHall, Englewood Cliffs, New Jersey.

Karlen D.L., Gardner J.C., Rosek, M.J. 1998. A soil quality framework for evaluating the impact of CRP. J. Prod Agric. 11, 56-60.

Klute, A. (Ed.), 1986. Water retention: laboratory methods. Methods of Soil Analysis, Part 1, $2^{\text {nd }}$ Ed. Agron. Monograph No. 9. ASA, Madison WI, pp.:635-661.

Lal, R. 1994. Methods and guidelines for assessing sustainable use of soil and water resources in the tropics. Soil Management Support System, USDA-NRCS, Washington, DC. pp:1-88.
Lal, R., Mokma, D., Lowery, B. 1999. Relation between soil quality and erosion, In: Lal, R. (ed.), Soil quality and soil erosion. Soil and Water Conservation Society, Ankeny, IO, pp: 237-258.

Larson, W.E., Pierce, F.J. 1994. The dynamics of soil quality as a measure of sustainable management. Defining Soil Quality for a Sustainable Environment. Soil Science Society of America, Madison, Wisconsin, pp: 37-52.

Lee, C. H., Wu, M. Y., Asio, V. B., Chen, Z. S., 2006.Using a soil quality index to assess the effects of applying swine manure compost on soil quality under a crop rotation system in Taiwan. Soil Sci. 171, 210-222.

Li, Y., Lindstorm, M.J. 2001. Evaluating soil quality-soil redistribution relationship on terraces and steep hillslope. Soil Sci Soc Am. J. 65, 1500-1508.

Lima, A.C.R., Hoogmoed, W.B., Brussaard, L. 2008. Soil quality assessment in rice production systems: establishing a minimum data set. J. Environ Qual. 37, 623-630.

Liu, Z., Zhou, W., Shen, J., Li, S., Ai, C. 2013. Soil quality assessment of yellow clayey paddy soils with different productivity. Biol Fert Soils, 50: (3), 537-548.

Mandal, U. K., Warrington, D. N., Bhardwaj, A. K., Bar-Tal, A., Kautsky, L., Minz, D., Levy, G.J. 2008. Evaluating impact of irrigation water quality on a calcareous clay soil using principal component analysis. Geoderma, 144, 189-197. 
Niu, L.A., Hao, J.M., Zhang, B.Z., Niu, X.S. 2011. Influences of Long-Term Fertilizer and Tillage Management on Soil Fertility of the North China Plain. Pedosphere. 21, 813-820.

Qi. Y., Jeremy, L.D., Huang, B., Zhao, Y., Sun, W., Gu, Z. 2009. Evaluating soil quality indices in an agricultural region of Jiangsu Province, China. Geoderma, 149, 325-334.

Rahmanipour, F., Marzaiolib, R., Bahrami, H. A., Fereidouni, Z., Rahimi Bandarabadi, S. 2014. Assessment of soil quality indices in agricultural lands of Qazvin Province, Iran. Ecol Indic. 40, 19-26.

Reynolds, W.D., Bowman, B.T., Drury, C.F., Tan, C.S., Lu, X. 2002. Indicators of good soil physical quality: density and storage parameters. Geoderma. 110, 131-146.

Reynolds, W.D., Drury, C.F., Tan, C.S., Fox, C.A., Yang, X.M. 2009. Use of indicators and pore volume-function characteristics to quantify soil physical quality. Geoderma. 152, 252-263.

Richards, L.A. 1954. Diagnosis and Improvement of Saline and Alkali Soils, L.A. Richards (eds). Handbook of U.S. Dept. of Agriculture, Washington, p: 4-160.

Salardini, A.A. 1996. Soil Fertility. Tehran University Publication. 5 th Ed. 440 p.

Scull, P., Okin, G. S. 2007. Sampling challenges posed by continental-scale soil landscape modeling. Sci Total Environ. 372, 645-656.

Shukla, M.K., Lal, R., Ebinger, M. 2006. Determining soil quality indicators by factor analysis. Soil Till Res. 87, 194-204.

Shukla, M.K., Lal, R., Ebinger, M. 2004. Principal component analysis for predicting corn biomass and grain yields. Soil Sci. 169, 215-224.
Singh, M.J., Khera, K.L. 2009. Physical indicators of soil quality in relation to soil erodibility under different land uses. Arid Land Res Manag. 23, 152-167.

Topp, G.C., Reynolds, W.D., Cook, F.J., Kirby, J.M., Carter, M.R. 1997. Physical attributes of soil quality. In: Gregorich, E.G., Carter, M.R. (Eds.), Soil Quality for Crop Production and Ecosystem Health. Dev Soil Sci. 25, 21- 58 .

Virto, I., Imaz, M.J., Mijangos, I., HernándezAllica, J., Fernández-Ugalde, O., Garbisu, C., Bescansa, P., Enrique, A. 2010. Soil quality in a semi-arid Mediterranean soil as affected by tillage system and residue burning. 19th World Congress of Soil Science, Soil Solutions for a Changing World, 1 - 6 August 2010, Brisbane, Australia.

Walkely A. and Black I.A., 1934. An examination of the Degtjareff method for determining soil organic matter and a proposed modification of the chromic acid titration method. Soil Sci. 37, 29-38.

Yang, J.E., Kim, S.C., Ok, Y.S., Lee, H.S., Kim, D.K., Kim, K.H. 2010. Determining minimum data set for soil quality assessment of organic farming system in Korea. In: 19th World Congress of Soil Science, Soil Solutions for a Changing World, 1-6 August 2010, Brisbane, Australia.

Yao, R., Yang, J., Gao, P., Zhang, J., Jin, W. 2013. Determining minimum data set for soil quality assessment of typical salt-affected farmland in the coastal reclamation area. Soil Till Res. 128, 137-148.

Yemefack, M., Jetten, V.G., Rossiter, D.G. 2006. Developing a minimum data ser for characterizing soil dynamics in shifting cultivation systems. Soil Till Res. 86, 84-98. 